SUPPLEMENT

\title{
A six year prospective study of the incidence and causes of head and neck injuries in international football
}

\author{
C W Fuller, A Junge, J Dvorak
}

Br J Sports Med 2005;39(Suppl I):i3-i9. doi: 10.1136/bjsm.2005.018937

\begin{abstract}
Objective: To identify those risk factors that have the greatest impact on the incidence of head and neck injuries in international football.

Method: A case-control study of players sustaining head and neck injuries during 20 FIFA tournaments (men and women) from 1998 to 2004. Video recordings of incidents were used to identify a range of parameters associated with the incidents. Team physicians provided medical reports describing the nature of each injury. $\chi^{2}$ tests $(p \leqslant 0.01)$ and $95 \%$ confidence intervals were used to assess differences in distribution and incidence of injury, respectively.

Results: In total, 248 head and neck injuries were recorded of which 163 were identified and analysed on video sequences. The commonest injuries were contusions (53\%), lacerations (20\%), and concussions (11\%). The incidence of all head and neck injuries was 12.5/1000 player hours (men 12.8, women 11.5) and 3.7 for lost-time injuries (men 3.5, women 4.1). The commonest causes of injury involved aerial challenges $(55 \%)$ and the use of the upper extremity $(33 \%)$ or head $(30 \%)$. The unfair use of the upper extremity was significantly more likely to cause an injury than any other player action. Only one injury (a neck muscle strain) occurred as a result of heading the ball throughout the 20 tournaments equivalent to 0.05 injuries/1000 player hours.

Conclusions: Players' actions most likely to cause a head or neck injury were the use of the upper extremity or the head but in the majority of cases these challenges were deemed to be fair and within the laws of the game.
\end{abstract}

See end of article for authors' affiliations

.....................

Correspondence to: C W Fuller, University of Leicester, Scarman Centre, Leicester, UK; cwf2@le.ac.úk
$\mathrm{T}$ he risk of concussion among athletes is a major concern in contact sports such as basketball, football, ice hockey, and rugby. ${ }^{1-4}$ There is also a concern that repeated concussive and non-concussive head trauma may lead to long term brain injury. ${ }^{5-8}$ In this context, only limited data are available on the incidence and causation factors associated with non-concussive head injuries in contact team sports. ${ }^{3}$ The risks associated with head injuries in football are recognised by the Fédération Internationale de Football Association (FIFA) and this is reflected in the national rules and laws for football of many member countries. For example in England, the Football Association" (FA), which states that "a head injury is a potentially serious injury which can lead, in a small number of cases, to significant complications. No head injury is trivial" ( $\mathrm{p} 407$ ), provides detailed guidelines on how club doctors should deal with head injuries.

Early epidemiological studies in football identified cognitive deficits among players that were attributed to repetitive trauma caused by heading the ball ${ }^{10}$; however, these results related to retrospective studies of players who had used the older, water absorbing heavier leather football. The validity of the conclusions from these, and also other studies, ${ }^{5}$ has been questioned, as possible confounding factors were not controlled. ${ }^{811} 12$ Later retrospective and prospective studies of players using the modern, water resistant lighter synthetic football failed to identify cognitive deficits among players. ${ }^{13-15}$ Many published studies on head and neck injuries in football present the data as the number or percentage of head or neck injuries ${ }^{13} 1617$ within sample populations or as the incidence of head and neck injuries in terms of athlete-exposures ${ }^{18}$ rather than as injuries per hours of exposure. Hawkins and Fuller $^{19}$ reported the incidence of head and neck injuries in English football as 1.4/1000 player hours (confidence interval (CI) 0.9 to 1.9; professional: 0.9 , CI 0.4 to 1.3; youth: 4.1 , CI 1.8 to 6.4 ) and Andersen et $a l^{20}$ reported the incidence in
Norwegian/Icelandic men's professional football as 1.7/1000 player hours. Faude $e t$ al $^{21}$ reported the incidence of head and neck injuries in German women's football as 1.8/1000 player hours (CI 0.7 to 2.9). In a Canadian study, Delaney et al ${ }^{17}$ reported that although $63 \%$ of players reported signs or symptoms associated with a concussion only $20 \%$ actually recognised that they had sustained a concussion. Barnes et $a l^{13}$ estimated that there was a $50 \%$ probability of each male player and a $22 \%$ probability of each female player sustaining a concussion over a 10 year playing career.

Video analysis is an extremely useful technique for examining a variety of issues in a range of sports ${ }^{22-25}$ because researchers can repeatedly and objectively observe and assess incidents. The versatility of video analysis for football research has been demonstrated in a wide range of applications. ${ }^{26-34}$ Although the technique has been used previously to assess the mechanisms of head and neck injuries in football, in one study ${ }^{29}$ the focus of the research was the impact of referees' decision making and in the another $^{20}$ the number of injuries assessed was small $(n=16)$.

This study aimed to use video analysis to determine the incidence and causation factors associated with head and neck injuries in international football as functions of players' sex, age, and injury diagnosis.

\section{METHOD}

In this research, an incident referred to any event that involved players challenging for possession of the ball or where a player was struck by the ball during the normal course of a match. Off-the-ball incidents, such as deliberate acts of violence, were not included in the analysis of injury causation factors. We defined injuries by the need for players to receive post-match medical attention (PMA) from their team physicians. Team physicians were required to complete a standardised injury report form ${ }^{35}$ for every case of PMA and 
Table 1 Diagnoses of all reported head and neck injuries and those analysed by video

\begin{tabular}{|c|c|c|c|c|c|c|}
\hline \multirow[b]{3}{*}{ Injury diagnosis } & \multicolumn{6}{|c|}{ Head/neck injuries (n (\%)) } \\
\hline & \multicolumn{3}{|c|}{ All injuries recorded by team physicians } & \multicolumn{3}{|c|}{ Injuries analysed on videotape } \\
\hline & Men & Women & All & Men & Women & All \\
\hline Concussion & $16(8)$ & $12(22)$ & $28(11)$ & $11(9)$ & $9(26)$ & 20 (12) \\
\hline Fracture/dislocation & $4(2)$ & $3(6)$ & $7(3)$ & $3(2)$ & $2(6)$ & $5(3)$ \\
\hline Contusion & $110(57)$ & $22(41)$ & $132(53)$ & $76(59)$ & $12(34)$ & $88(54)$ \\
\hline Laceration/abrasion & $41(21)$ & $8(15)$ & $49(20)$ & $31(24)$ & $6(17)$ & $37(23)$ \\
\hline Others & $23(12)$ & $9(17)$ & $32(13)$ & $7(5)$ & $6(17)$ & $13(8)$ \\
\hline Total & 194 & 54 & 248 & 128 & 35 & 163 \\
\hline
\end{tabular}

submit the form to FIFA's Medical Assessment and Research Centre.

\section{Incident assessment}

We analysed incidents resulting in head/neck injuries in 20 FIFA tournaments ( 14 men, 6 women) over the period 19982004. The FIFA provided video recordings for each match from the following tournaments:

- Men: 1998 World Cup; 1999 Confederation Cup; 1999 U17 World Championship; 1999 U-20 World Championship; 2000 Club World Championship; 2000 Olympic Games; 2001 Confederation Cup; 2001 U-17 World Championship; 2001 U-20 World Championship; 2002 World Cup; 2003 Confederation Cup; 2003 U-17 World Championship; 2003 U-20 World Championship; 2004 Olympic Games

- Women: 1999 World Cup; 2000 Olympic Games; 2002 U19 World Championship; 2003 World Cup; 2004 Olympic Games; 2004 U-19 World Championship

Six risk factors, which have been used previously to assess injury mechanisms, ${ }^{29}$ were analysed for each incident:

- position on the pitch where the incident occurred with respect to the injured player (defending penalty area, defending half of the pitch excluding the penalty area, attacking half of the pitch excluding the penalty area, attacking penalty area)

- ball possession status at the time of the incident (injured player in possession, other player in possession, free ball)

- direction of approach on the injured player by the noninjured player (front, side, behind; injured player struck by ball)

- mode of approach by non-injured player (staying on feet, sliding in including jumping horizontally, jumping vertically; injured player struck by ball)

- action (non-injured player using one/two footed tackle, arm/hand, upper body, head; injured player struck by ball)

- intent of the non-injured player at the time of incident (for example raised elbow with clear movement of the elbow into the injured player's face-unfair act; two players accidentally clashing heads while jumping to head the ball-fair act).

We also recorded the match referee's decision (non-foul, foul), the object/body part striking the injured player (head, upper extremity, lower extremity, trunk, ball, ground, goal post/corner flag) and the point of contact on the injured player's head/neck (front, side, back, top, no contact) for each incident.

\section{Injury assessment}

PMA reports, which were based on the team physician's clinical judgement, provided the injury:
- location (head, neck)

- diagnosis (concussion, contusion, dental, dislocation, fracture, laceration/abrasion, sprain, strain)

- severity (number of days unavailable for training and/or competition: no lost time, slight (1-3 days), minor (47 days), moderate ( $>1$ week to 1 month), major $(>1$ month)).

We defined incidence as the number of incidents per 1000 player hours, based on 22 players per game and each match lasting for 90 minutes unless extra time was played. ${ }^{35}$

\section{Interrater reliability}

The overall interrater reliability for identifying incident parameters using the video analysis protocol has been reported previously ${ }^{32}$ as $95 \%$. In addition, two observers independently assessed the non-injured player's intent during $50 \%$ of the incidents and recorded an interrater reliability of $85 \%$.

\section{Data analysis}

We used $\chi^{2}$ tests to identify differences between the distributions of injuries for the six different risk factors as functions of sex, age, and injury diagnosis. Because the probability of type I errors increases with the number of hypotheses tested, statistical significance was only accepted at $p \leqslant 0.01$; however, $p$ values are provided where the $p$ value for non-significant tests was $\leqslant 0.05$. Significant differences between the incidence of injury for men and women and between tournaments were determined by whether the $95 \%$ confidence intervals overlapped.

\section{RESULTS}

The study included 19802 player hours of match exposure (men 15 115, women 4687), which represented 91\% of the total player hours in the 20 tournaments. A total of 1633 incidents of PMA were recorded of which 237 (14.5\%) were to the head and $11(0.7 \%)$ were to the neck. Of the 248 injuries to the head and neck, $194(78.2 \%)$ were sustained by men and $54(21.8 \%)$ by women. Of the 248 incidents, 163 were identified on videotape (men 128, women 35 ) and also met the criteria for inclusion in the analysis. There were no significant differences between the diagnoses of the PMAs analysed on video tape and the diagnoses of all the head/neck injuries reported by the team physicians (table 1) for either men or women. There were, however, significant differences $(p<0.001)$ between the diagnoses for men and women. There was no significant difference $(p=0.16)$ between the proportion of men $(24 \%)$ and women $(34 \%)$ who were substituted either immediately following the injury or later in the game.

The overall incidence of head/neck injuries was 12.5 (CI 10.9 to 14.1 ) per 1000 player hours (men: 12.8, CI 11.0 to 14.7; women: 11.5, CI 8.4 to 14.6). The incidence of lost-time 


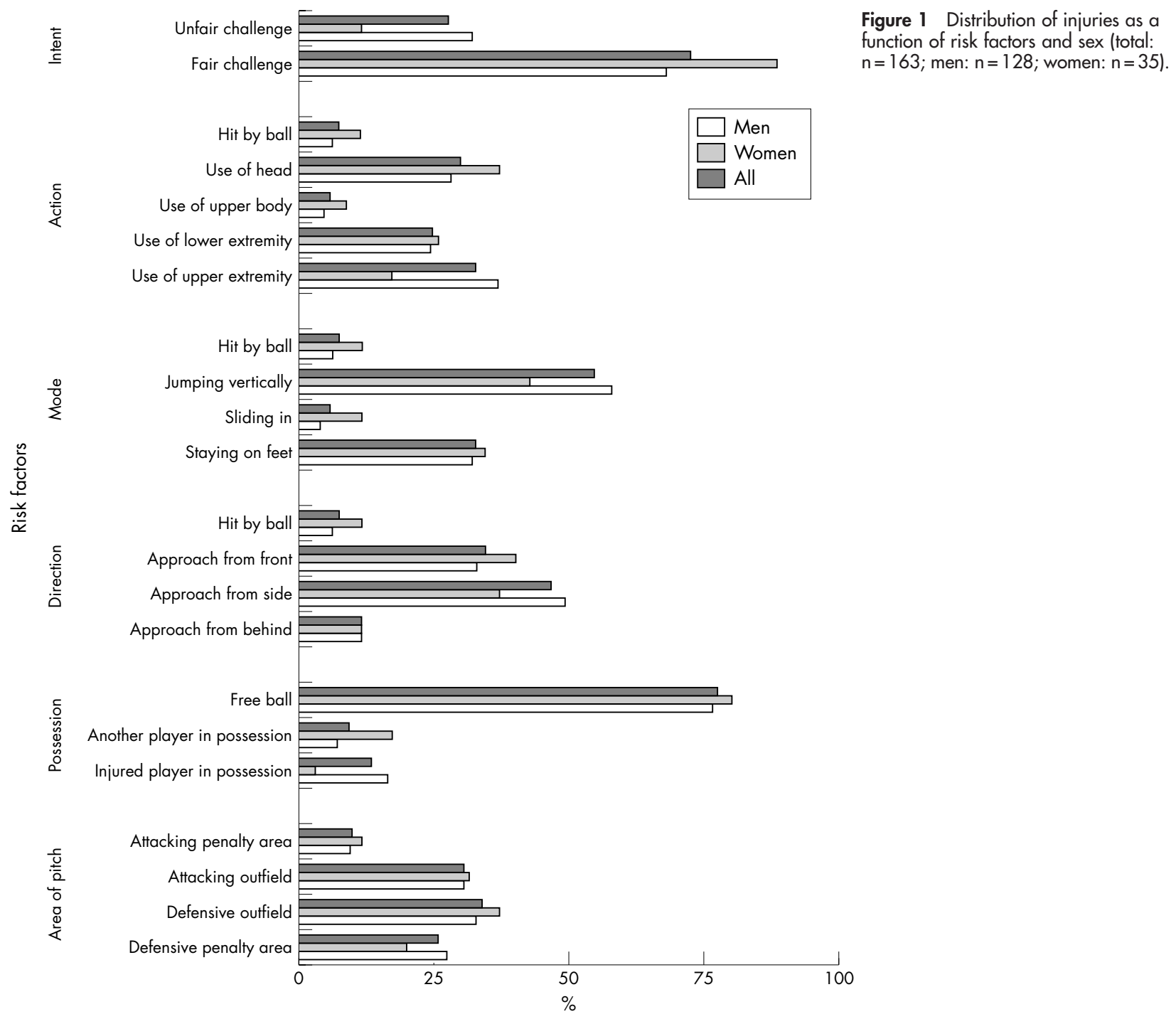

head/neck injuries was 3.7 (CI 2.7 to 4.7 ) per 1000 player hours (men: 3.5, CI 2.4 to 4.6; women: 4.1, CI 2.1 to 6.1). Seventy per cent of the PMAs did not result in loss of time, $21 \%$ were classified as slight, $6 \%$ as minor, $3 \%$ as moderate,

\begin{tabular}{|c|c|c|c|c|}
\hline \multirow[b]{3}{*}{ Tournament } & \multicolumn{4}{|c|}{$\begin{array}{l}\text { Incidence of injuries } \\
\text { per } 1000 \text { player hours }\end{array}$} \\
\hline & \multicolumn{2}{|c|}{ All injuries } & \multicolumn{2}{|c|}{ Lost-time injuries } \\
\hline & Men & Women & Men & Women \\
\hline $\begin{array}{l}\text { Under-17 World } \\
\text { Championship }\end{array}$ & 11.1 & - & 4.1 & - \\
\hline Under-19 World & - & 11.1 & - & 4.7 \\
\hline $\begin{array}{l}\text { Championship } \\
\text { Under-20 World } \\
\text { Championship }\end{array}$ & 15.8 & - & 4.1 & - \\
\hline Olympic Games & 16.8 & 13.2 & 3.8 & 4.4 \\
\hline Club World Championship & 9.6 & - & 3.2 & - \\
\hline Confederations Cup & 10.7 & - & 1.9 & - \\
\hline World Cup & 10.1 & 10.9 & 2.4 & 2.8 \\
\hline All tournaments & 12.8 & 11.5 & 3.5 & 4.1 \\
\hline
\end{tabular}

and $0 \%$ as major: the injuries categorised as moderate were diagnosed as concussions, nose fractures, and a combined concussion/fracture. Table 2 shows the incidence of injuries for men and women as a function of each type of tournament.

There was a significant difference $(p<0.001)$ in the numbers of PMAs as a function of the point of contact on the head/neck (back: 18 (11\%); side: 61 (37\%); front: 81 (50\%); top: 1 ( $1 \%)$; no contact: $2(1 \%))$. There was also a significant difference $(\mathrm{p}<0.001)$ in the numbers of injuries as a function of the object contacting the head/neck (head: 49 (30\%); upper extremity: 57 (35\%); lower extremity: 35 (21\%); trunk: $3(2 \%)$; ball: $14(9 \%)$; ground: $3(2 \%)$; no contact: 2 $(1 \%))$. The two injuries that did not involve contact were both neck injuries sustained by female players and were probably caused by hyperextension followed by flexion (whiplash action). The distribution of injuries as a function of playing position was significantly different for men $(\mathrm{p}=0.002$; goalkeeper: 19 (15\%); defender: 51 (40\%); midfielder: $28(22 \%)$; forward: $30(23 \%))$ but not significantly different for women $(\mathrm{p}=0.44$; goalkeeper: $3(9 \%)$; defender: 12 (34\%); midfielder: 10 (29\%); forward: 10 (29\%)) when compared with the distributions predicted for a team consisting of one goalkeeper, four defenders, four midfielders, and two forwards. 


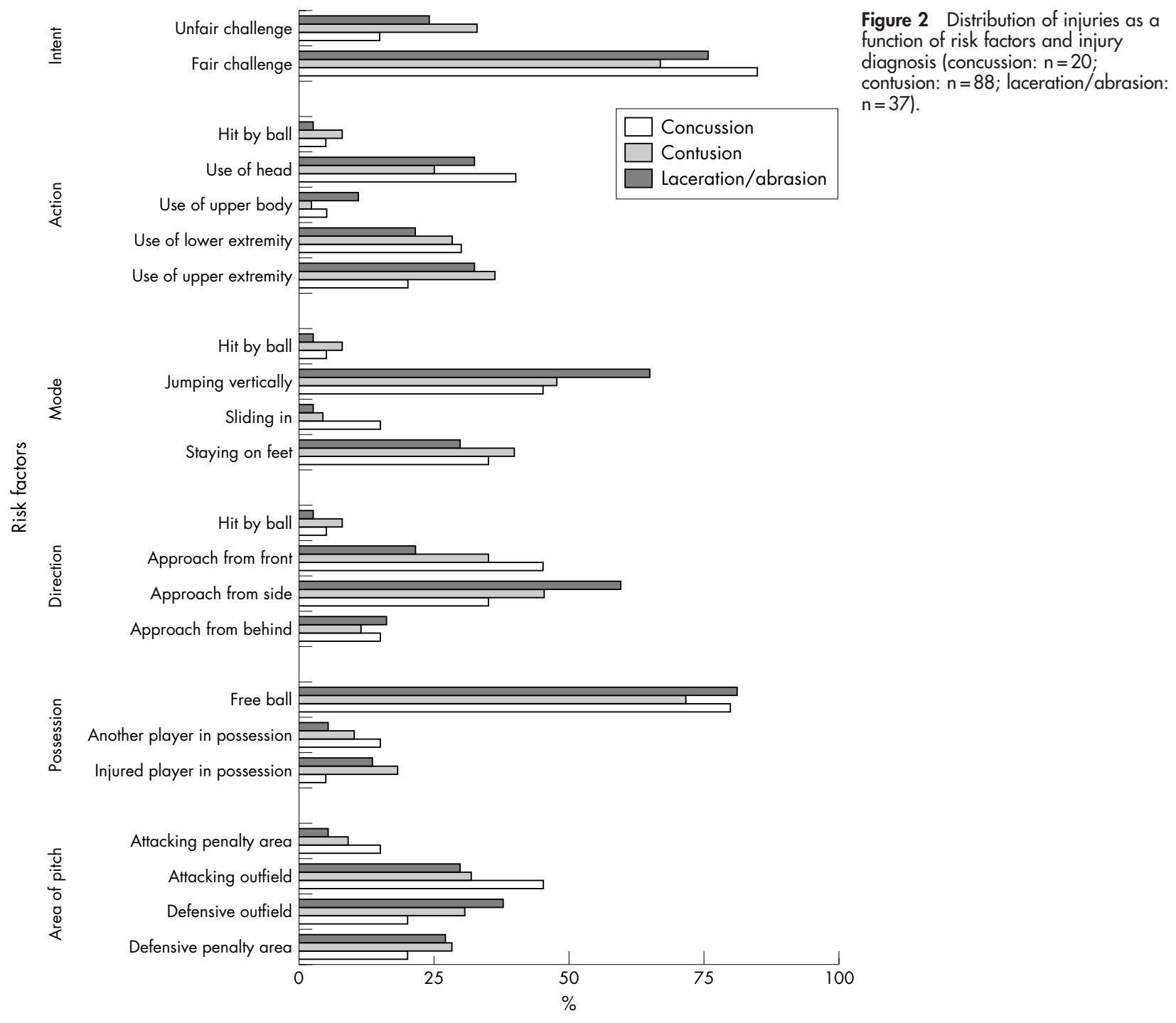

The distributions of head/neck PMAs as functions of the risk factors and sex are shown in fig 1 . There were significant differences between men and women for possession status $(p=0.01)$ and intent $(p=0.009)$. Non-significant differences were observed in the distributions for the mode of approach $(p=0.05)$ and the number of head/neck injuries assessed on the pitch at the time of injury (women: 93\%, men: 77\%; $\mathrm{p}=0.04$ ). Match referees deemed that $30 \%$ of the incidents analysed that led to a head/neck injury were foul challenges (men: 31\%; women: 27\%).

The distributions of head/neck PMAs as functions of risk factors and the three most common injury diagnoses are shown in fig 2 . There was only one injury that resulted from a player heading the ball and this injury did not result in loss of time: the injury was a strain/sprain of the neck of a male defender during an under-17 match that occurred while the player attempted to head a ball that had been crossed into his penalty area. The player did not receive treatment at the time of the injury. There was one concussion recorded as a consequence of a player being hit by the ball: this injury was caused by close range impact of the ball on the side of a male player's head after a defender had kicked the ball to clear it upfield. On the other hand, there were 49 injuries resulting from head to head contact, of which 8 (men: 3; women: 5) were concussions. There were no significant differences observed for any of the risk factors when comparing concussion injuries with all other injuries. None of the incidents resulting in concussion were considered to be the result of a deliberate action and none were deemed to be a foul by the match referee. Of the players sustaining a concussion $89 \%$ were treated on the pitch at the time of the injury compared with $79 \%$ for all other injuries to the head/ neck.

The distributions of head/neck PMAs as functions of risk factors and age (youth players: U-17, U-19, and U-20 tournaments; senior players: all other tournaments) are shown in fig 3. There were no significant differences in the distributions of any of the risk factors (location on pitch: $\mathrm{p}=0.04)$.

A contingency table comparing the non-injured player's intent during challenges that involved the use of the upper extremity with the non-injured player's intent during challenges involving all other actions is shown in table 3. The distributions were significantly different for both men $(\mathrm{p}<0.001)$ and women $(\mathrm{p}=0.001)$.

\section{DISCUSSION}

The overall incidence of injury in football is generally higher at the elite level of play ${ }^{36}$ and therefore the incidence of injury reported here is likely to be higher than that encountered 


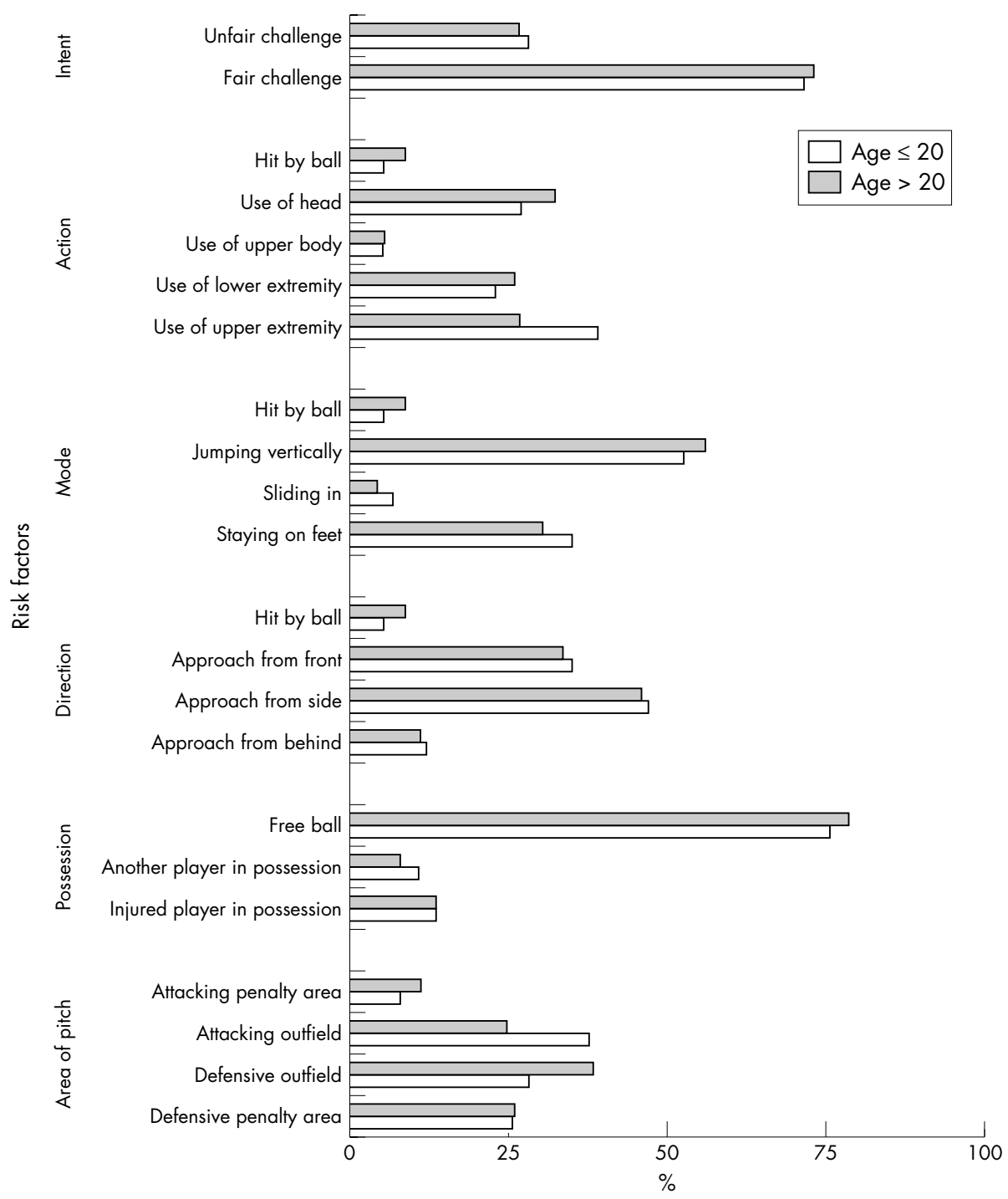

Figure 3 Distribution of injuries as a function of risk factors and age of players (youth: $n=74$; senior: $n=89$ ).

among recreational players. Head/neck injuries represented $15 \%$ of all recorded PMAs and 10\% of all lost-time PMAs, which compared with previously reported values of $4-20 \%$. The incidence of lost-time head/neck injuries for men (3.5 per 1000 player hours) in the present study is significantly higher than that reported by Hawkins and Fuller $(1.4)^{19}$ but the value for women (4.1) is not significantly different from that reported by Faude et al (1.8). ${ }^{21}$ We found the incidence of concussion in women $(2.6)$ to be 2.4 times higher than that

Table 3 Contingency table showing the distribution of injuries as a function of the action and fairness of challenges by the non-injured player for men $(n=128)$ and women $(n=35)$

\begin{tabular}{|c|c|c|c|c|}
\hline \multirow{3}{*}{$\begin{array}{l}\text { Action of non-injured } \\
\text { player in challenge }\end{array}$} & \multicolumn{4}{|c|}{$\begin{array}{l}\text { Fairness of challenge by non-injured playe } \\
\text { (No of injuries }(\%) \text { ) }\end{array}$} \\
\hline & \multicolumn{2}{|l|}{ Men } & \multicolumn{2}{|l|}{ Women } \\
\hline & Fair & Unfair & Fair & Unfair \\
\hline $\begin{array}{l}\text { Use of upper extremity } \\
\text { All other actions }\end{array}$ & $\begin{array}{l}20(16) \\
67(52)\end{array}$ & $\begin{array}{l}27(21) \\
14(11)\end{array}$ & $\begin{array}{l}3(9) \\
28(80)\end{array}$ & $\begin{array}{l}3(9) \\
1(3)\end{array}$ \\
\hline
\end{tabular}

in men (1.1). This compares closely with the results reported by Delaney et $a l^{17}$ that women are 2.5 times more likely to experience a concussion than men but differs from the results of Barnes et $a l^{13}$ that men are 2.2 times more likely to experience a concussion than women. However, the conclusions of the earlier studies were based on numbers of injuries recorded over fixed time periods rather than on hours of exposure: the apparent increase in the probability of women experiencing a concussion between 1993 and 1999 may therefore simply reflect an increased level of exposure.

A player's role in the modern game of football changes constantly throughout a game so it is difficult to define the exact role of a player, in terms of their playing position, at the time of injury. However, based on the declared positions of players at each tournament, ${ }^{37}$ goalkeepers and forwards sustained more and midfielders fewer of all types of head/ neck injury than would be predicted for a team based on a 1:4:4:2 formation. This may reflect the greater risks that players in these positions are prepared to take in order to achieve their key objectives of preventing and scoring goals, respectively.

In the present study, throughout the 20 tournaments, only one injury (neck muscle strain) resulted from a player heading the ball; this represents an incidence of acute injury from heading of only $0.05 / 1000$ player hours. There was also 


\begin{tabular}{|c|c|c|c|c|c|c|}
\hline \multirow[b]{3}{*}{ Group } & \multicolumn{6}{|c|}{ Commonest cause of injury } \\
\hline & \multicolumn{6}{|l|}{ Risk factor } \\
\hline & $\begin{array}{l}\text { Location of } \\
\text { incident on pitch }\end{array}$ & $\begin{array}{l}\text { Possession } \\
\text { status prior } \\
\text { to challenge }\end{array}$ & $\begin{array}{l}\text { Direction of } \\
\text { challenge }\end{array}$ & $\begin{array}{l}\text { Mode of } \\
\text { challenge }\end{array}$ & $\begin{array}{l}\text { Action during } \\
\text { challenge }\end{array}$ & Intent \\
\hline \multicolumn{7}{|l|}{ Sex } \\
\hline Men & Defensive ouffield & Free ball & From the side & Jumping & $\begin{array}{l}\text { Use of upper } \\
\text { extremity }\end{array}$ & Fair challenge \\
\hline Women & Defensive outfield & Free ball & From the front & Jumping & Use of head & Fair challenge \\
\hline \multicolumn{7}{|l|}{$\begin{array}{l}\text { Tournaments for } \\
\text { players aged: }\end{array}$} \\
\hline$\leqslant 20$ years & Attacking outfield & Free ball & From the side & Jumping & $\begin{array}{l}\text { Use of upper } \\
\text { extremity }\end{array}$ & Fair challenge \\
\hline $\begin{array}{c}>20 \text { years } \\
\text { Injury diagnosis }\end{array}$ & Defensive outfield & Free ball & From the side & Jumping & Use of head & Fair challenge \\
\hline Concussion & Attacking outfield & Free ball & From the front & Jumping & Use of head & Fair challenge \\
\hline Contusion & Attacking outfield & Free ball & From the side & Jumping & $\begin{array}{l}\text { Use of upper } \\
\text { extremity }\end{array}$ & Fair challenge \\
\hline $\begin{array}{l}\text { Laceration/ } \\
\text { abrasion }\end{array}$ & Defensive outfield & Free ball & From the side & Jumping & $\begin{array}{l}\text { Use of head or } \\
\text { upper extremity }\end{array}$ & Fair challenge \\
\hline
\end{tabular}

only one incident where a player experienced concussion after being struck by the ball. On the other hand, 49 injuries resulted from head to head contact (2.6 injuries per 1000 player hours), of which $16 \%$ were concussions. These results support the contentions of Kirkendall et al ${ }^{11}$ and McCrory ${ }^{38}$ that heading a modern football represents a much lower risk than head to head contact. Kirkendall et al ${ }^{11}$ emphasised the special skills that should be developed by players to head a football correctly to minimise the risk of injury. It could also be hypothesised that players would learn from experience which situations to avoid as likely to lead to injury when attempting to head the ball. This knowledge is more likely to be acquired with age than through practice; however, we did not find any significant differences in the distributions of any of the risk factors between the youth and senior players.

The specific aim of our study was to identify those risk factors that had the greatest impact on the incidence of head/ neck injuries in football as a function of players' sex, age, and injury diagnosis. The location on the pitch and the context of the ball will influence the way in which a player approaches a challenge. For example, the location defines the relative importance of the situation: a player's main objective in the defensive penalty area will be to avoid conceding a goal, in the attacking penalty area to score a goal, and in the defensive or attacking outfields to gain or keep control of the ball to prevent or create an attacking opportunity. Whether a player has possession, an opponent has possession, or no-one has possession of the ball will determine the strategy that players adopt to maintain or gain control of the ball. The direction of approach to a situation and the mode of challenge for the ball define how players attempt to maintain or gain control of the ball. Finally, the specific actions employed by players and their intent during these actions reflect individual players' attitudes towards the concept of "fair play". The dominant parameters leading to PMAs for each of the risk factors as functions of sex, age, and injury diagnosis derived from figs $1-3$ are summarised in table 4 .

\section{What is already known on this topic}

Recent reports have claimed that heading a modern football represents a much lower risk of injury than head to head contact.
These results support some previous hypotheses about the causes of head/neck injury but disagree with others. For example, in terms of pitch location, Kirkendall et al ${ }^{11}$ suggested that "The most likely sites on the field for a head injury are within the penalty area when many players are competing for a cross or corner kick or when an on-rushing forward and goalkeeper collide" (p 372). Although these scenarios were certainly encountered in the present study, the penalty area did not represent the commonest location for injury. Boden et al $^{18}$ identified head to head contact as the major causation factor in concussion injuries and this mechanism was common in the present study. Other authors have identified unfair use of the upper extremity as a significant cause of head/neck injuries ${ }^{20} 29$ and our results support this contention. Kirkendall et al ${ }^{11}$ discussed the role of impacts to the side of the head as an important injury causation factor because of the rotational forces generated on the head; in the present study more injuries were indeed caused by challenges from the side.

Our analysis of risk factors identified a consistency in the causation of head/neck injuries. Firstly, the majority of injuries occurred in incidents that took place in what might be considered to be low risk areas of the football pitch, namely the defensive and attacking outfields, rather than in the highly critical penalty areas, where matches can be won or lost through the risks that players are prepared to take. Secondly, the majority of injuries occurred as a consequence of aerial challenges, from the side or front, for a high, free ball. Finally, the players' actions most likely to cause injury were the use of the upper extremity or the head but in the majority of cases the challenges were deemed to be fair and within the current laws of the game.

\section{What this study adds}

The incidence of head and neck injuries caused by heading the ball was extremely low. The use of the upper extremity and head to head contact during aerial challenges were the major causes of head and neck injuries. The majority of contacts leading to head and neck injuries were deemed by match referees to be within the laws of the game. 


\section{ACKNOWLEDGEMENTS}

The authors would like to acknowledge the invaluable assistance provided in the preparation of the post-match injury report forms by the physicians from the international teams taking part in the 20 FIFA tournaments covered by this study.

\section{Authors' affiliations}

C W Fuller, University of Leicester, Leicester, UK

A Junge, J Dvorak, Schulthess Clinic, Zurich, Switzerland

Competing interests: none declared

\section{REFERENCES}

1 Cantu RC. Head injuries in sport. Br J Sports Med 1996;30:289-96.

2 Woitys EM, Hovda D, Landry G, et al. Concussion in sport. Am J Sports Med 1999:27:676-87.

3 Johnston KM, McCrory P, Mohtadi NG, et al. Evidence-based review of sportrelated concussion: clinical science. Clin J Sport Med 2001;11:150-9.

4 Aubry M, Cantu R, Dvorak J, et al. Summary and agreement statement of the first International Conference on Concussion in Sport, Vienna 2001. Br J Sports Med 2001;36:6-10.

5 Matser JT, Kessel AGH, Jordan BD, et al. Chronic traumatic brain injury in professional soccer players. Neurology 1998;51:791-6.

6 Collie A, Darby D, Maruff P. Computerised cognitive assessment of athletes with sports related head injury. Br J Sports Med 2001;35:297-302.

7 Rutherford A, Stephens R, Potter D. The neuropsychology of heading and head trauma in association football (soccer): a review. Neuropsychology Rev 2003;13:154-79

8 Demetriades AK, McEvoy AW, Kitchen, ND. Subdural haematoma associated with an arachnoid cyst after repetitive heading injury in ball games. $\mathrm{Br} J$ Sports Med 2003;30:289-96

9 Football Association. Rules of the Association and Laws of the Game: Season 2004-2005. London: The Football Association, 2004.

10 Tysvaer AT. Head and neck injuries in soccer: impact of minor head trauma. Sports Med 1992;14:200-13.

11 Kirkendall DT, Jordan SE, Garrett WE. Heading and head injuries in soccer. Sports Med 2001;31:369-86.

12 Putukian M. Heading in soccer. Is it safe? Curr Sports Med Rep 2004;3:9-14.

13 Barnes BC, Cooper L, Kirkendall DT, et al. Concussion history in elite male and female soccer players. Am J Sports Med 1998;26:433-8.

14 Putukian M, Echemendia R, Mackin S. The acute neuropsychological effects of heading in soccer. Clin J Sports Med 2000;10:104-9.

15 Guskiewicz K, Maskell S, Broglio S, et al. No evidence of impaired neurological performance in collegiate soccer players. Am J Sports Med 2002;30:157-62

16 Lewin G. The incidence of injury in an English professional football club during one competitive season. Physiotherapy 1989;75:601-5.
17 Delaney JS, Lacroix VJ, Leclerc S, et al. Concussion among university football and soccer players. Clin J Sports Med 2002;12:331-8.

18 Boden BP, Kirkendall DT, Garrett WE. Concussion incidence in elite college soccer players. Am J Sports Med 1998;26:238-41.

19 Hawkins RD, Fuller CW. A prospective epidemiological study of injuries in four English professional football clubs. Br J Sports Med 1999;33:196-203.

20 Andersen TE, Arnason A, Engebretsen L, et al. Mechanisms of head injuries in elite football. Br J Sports Med 2004;38:690-6.

21 Faude $O$, Junge A, Kindermann W, et al. Injuries in female soccer players: a prospective study in the German national league. Am J Sports Med (in press).

22 Ettlinger CF, Johnson RJ, Shealy JE. A method to help reduce the risk of serious knee sprains incurred in alpine skiing. Am J Sports Med 1995;23:531-7.

23 Hawkins RD, Fuller CW. Risk assessment in professional football: an examination of accidents and incidents in the 1994 World Cup finals. Br J Sports Med 1996;30:165-70.

24 McCrory PR, Bladin PF, Berkovic SF. Retrospective study of concussive convulsions in elite Australian rules and rugby league footballers: phenomenology, aetiology, and outcome. BMJ 1997;314:171-4.

25 Wilson BD, Quarrie KL, Milburn PD, et al. The nature and circumstances of tackle injuries in rugby union. J Sci Med Sport 1999;2:153-62.

26 Fuller CW, Hawkins RD. Assessment of football grounds for player safety. Saf Sci 1997;27:115-28.

27 Hawkins RD, Fuller CW. An examination of the frequency and severity of injuries and incidents at three levels of professional football. Br J Sports Med 1998:32:326-32.

28 Rahnama N, Reilly T, Lees A. Injury risk associated with playing actions during competitive soccer. Br J Sports Med 2002;36:354-9

29 Fuller CW, Smith GL, Junge A, et al. An assessment of player error as an injury causation factor in international football. Am J Sports Med 2004;32:28S-35S

30 Fuller CW, Junge A, Dvorak J. An assessment of football referees' decisions in incidents leading to player injuries. Am J Sports Med 2004;32:17S-22S

31 Andersen TE, Larsen $\mathrm{O}$, Tenga A, et al. Football incident analysis: a new video based method to describe injury mechanisms in professional football. Br J Sports Med 2003;37:226-32.

32 Fuller CW, Smith GL, Junge A, et al. The influence of tackle parameters on the propensity for injury in international football. Am J Sports Med 2004;32:43S-53S

33 Giza E, Fuller CW, Junge A, et al. Mechanisms of foot and ankle injuries in soccer. Am J Sports Med 2003;31:550-4.

34 Andersen TE, Floerenes TW, Arnason A, et al. Video analysis of the mechanisms for ankle injuries in football. Am J Sports Med 2004:32:69S-79S

35 Junge A, Dvorak J, Graf-Baumann T, et al. Football injuries during FIFA tournaments and the Olympic games, 1998-2001. Am J Sports Med 2004;32:80S-89S

36 Dvorak J, Junge A. Football injuries and physical symptoms. A review of the literature. Am J Sports Med 2000;28:S3-S9.

37 Fédération Internationale de Football Association (FIFA). Reports and Statistics of FIFA Tournaments. 2004; available at, www.fifa.com.

38 McCrory PR. Brain injury and heading in soccer. BMJ 2003;327:351-2. 